\title{
AN EXPERIMENT OF GB-SAR INTERPEROMETRIC MEASUREMENT OF TARGET DISPLACEMENT AND ATMOSPHERIC CORRECTION
}

\author{
Hoonyol Lee*, Jae-Hee Lee*, Seong-Jun Cho**, Nak-Hoon Sung**, and Jung-Ho Kim** \\ * Department of Geophysics, Kangwon National University, Hyoja-dong, Chuncheon, Republic of Korea \\ ** Korea Institute of Geoscience and Mineral Resources, Gajung-dong, Daejeon, Republic of Korea \\ emails: [hoonyol, zackvoice]@kangwon.ac.kr, [mac, nhsung, jungho]@kiagm.re.kr
}

\begin{abstract}
We made a ground-based synthetic aperture radar (GBSAR) system and tested its interferometric SAR (InSAR) measurement on the displacement of a trihedral corner reflector with atmospheric correction in terms of humidity and range. The GB-SAR worked at C-band with the synthetic aperture length of $5 \mathrm{~m}$. Fully-polarimetric images were obtained with resolutions of $25 \mathrm{~cm}$ in range and 0.32 degree in azimuth direction. Located $160 \mathrm{~m}$ away from the system, the reflector was moved from $1 \mathrm{~mm}$ to $40 \mathrm{~mm}$ toward the system during each acquisition. An atmospheric correction function was obtained in terms of humidity and range by analyzing the phase of several stationary targets. The result showed an atmospheric delay of $3 \mathrm{~mm}$ at $160 \mathrm{~m}$ range when humidity changed from $47 \%$ to $58 \%$. After atmospheric correction, DInSAR error was less than $1 \mathrm{~mm}$ with the correlation coefficient of 0.9999 when compared with the actual displacements. We concluded that atmospheric correction should be reinforced somehow for most spaceborne InSAR applications.
\end{abstract}

Index Terms - GB-SAR, interferometry, displacement measurement, atmospheric correction.

\section{INTRODUCTION}

A GB-SAR (Ground-Based Synthetic Aperture Radar) applies the aperture-synthesizing principles of satellite or airborne SAR system on the ground rail system. The system inherits the advantages of SAR in obtaining high resolution images regardless of energy source or weather condition. Moreover the GB-SAR can provide precision imaging continuously at the same imaging configuration, say, zerobaseline with small temporal baseline of several minutes [1][2]. For these advantages, GB-InSAR (GBInterferometric SAR) measurement have been applied to various research fields such as measuring ground subsidence, perceiving avalanche, evaluating stability of building or dam, and investigating polarimetric response of natural targets [3]-[7].

Recent developments of spaceborne SAR interferometric techniques are often hampered by the lack of atmospheric information and larger temporal baseline of several days to months. Humidity and temperature change is the major source of propagation delay of electromagnetic wave, which should be compensated for in most InSAR applications.

In this experiment, we measured movement of a trihedral corner reflector by using GB-InSAR and compared the results with the actual displacements. Mismatches were found between them, which have high correlation with humidity changes. Using phase signals from several stationary targets, we constructed an atmospheric correction term as a function of range and humidity, once for all polarization and another for each polarization. These functions were applied to correct the GB-InSAR displacement measurement, which explained most of the errors. Lastly, we compared the atmospheric correction terms with those of [8] that used X-band GB-InSAR for atmospheric correction.

\section{GB-SAR DISPLACEMENT MEASUREMENT}

The experiment was performed between $3 \mathrm{pm}$ and 6:30 pm on 18 July 2007 at Korea Institute of Geoscience and Mineral Resources (KIGAM), Daejeon, Korea. The GBSAR system was installed on the roof of the building (Fig. 1) and operated with the system parameters as listed in Table I. Agilent 8753ES vector network analyzer was used to obtain range resolution by stepped-frequency sweeping. A microwave switch selected the polarization ports of the two C-band dual-polarization square horn antennas so that fully-polarimetric images can be acquired. A microwave amplifier was used to raise the power to $33 \mathrm{dBm}(2 \mathrm{~W})$. All equipments were onboard a vehicle and there is no distortion in the RF cables during image acquisition. Inhouse software was used to focus the data by using the Deramp-FFT algorithm [2].

Fig. 2 shows the test site and the image area taken by IKONOS satellite. Fig. 3 is the VV-polarization image as an example. Trees on two hills between $90 \mathrm{~m}$ and $120 \mathrm{~m}$ range show high reflection. Geomagnetic observatories $(100 \mathrm{~m}$ range) that appear white in Fig. 2 have high backscattering in Fig. 3. We selected one tree at $90 \mathrm{~m}$ and three 
observatories at $120 \sim 150 \mathrm{~m}$ as a stationary targets for atmospheric correction, which were indicated in Fig. 2. At $160 \mathrm{~m}$ range, we put a trihedral corner reflector on an acrylic plate to control the displacement, as shown in Fig. 2. In-between GB-SAR observations we moved the reflector by $1,6,10,30$, and $40 \mathrm{~mm}$ from the original position toward the system.

TABLE I. GB-SAR IMAGING PARAMETERS.

\begin{tabular}{|c|c|}
\hline Frequency & $5.0-5.6 \mathrm{GHz}$ \\
\hline Range resolution & $25 \mathrm{~cm}$ \\
\hline Maximum Range & $200 \mathrm{~m}$ \\
\hline Power & $33 \mathrm{dBm}$ \\
\hline Synthetic aperture length & $5 \mathrm{~m}$ \\
\hline Azimuth step & $5 \mathrm{~cm}$ \\
\hline Azimuth Resolution & 0.32 degree \\
\hline Azimuth Image width & 32 degree \\
\hline
\end{tabular}

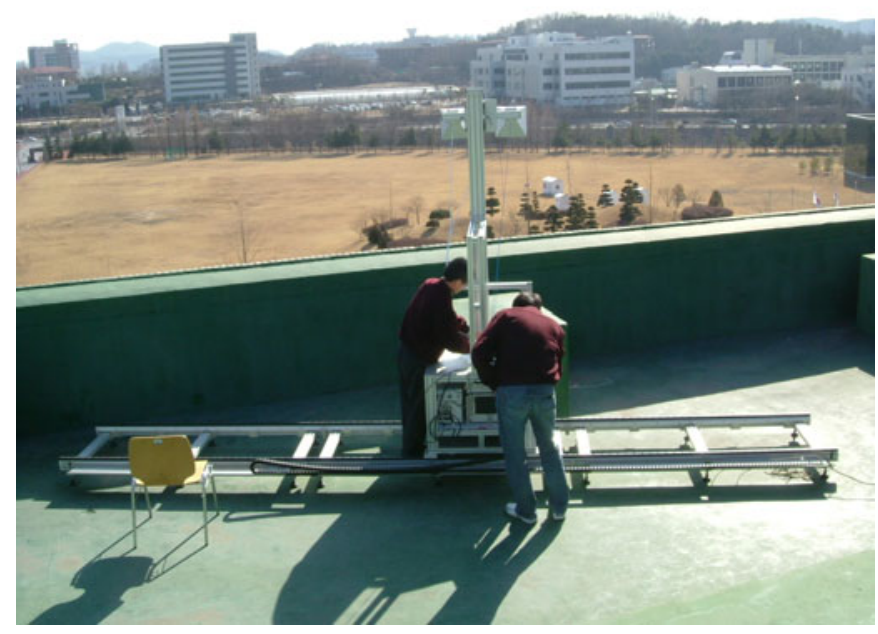

Fig. 1. GB-SAR system and field view of test site.

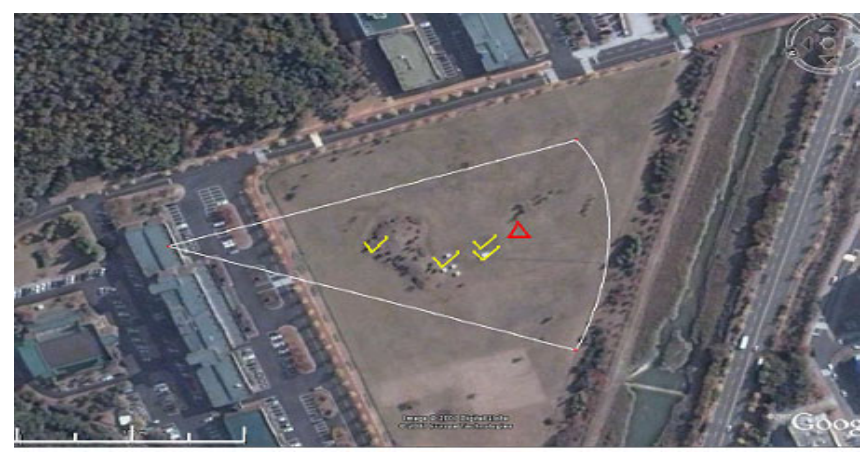

Fig. 2. Image area of GB-SAR (CGoogle Earth)

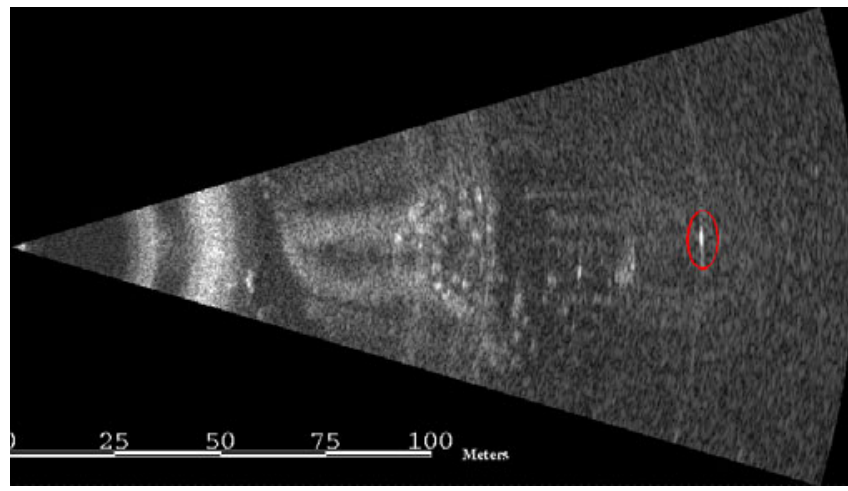

Fig. 3. The GB-SAR VV image (the reflector in a circle).

When a target moves in range direction $R$, the interferometric phase $\phi$ changes by the following rate,

$$
\frac{\partial \phi}{\partial R}=-\frac{4 \pi}{\lambda}
$$

where $\lambda$ is the wavelength. With the center frequency of 5.3 $\mathrm{GHz}$, this system has -12.7 degree $/ \mathrm{mm}$. We extracted phase of the reflector, unwrapped if necessary, converted it to the displacement, and compared them with the actual displacements (Fig. 4). They generally correlate very well with $\mathrm{R}^{2}$ values of 0.9995 to 0.9996 and rms error of more than $1 \mathrm{~mm}$ except VH (Table II). However, there existed anomalies of $2 \sim 3 \mathrm{~mm}$ at the $40 \mathrm{~mm}$ maximum displacement. The GB-SAR displacement was $2 \sim 3 \mathrm{~mm}$ shorter than the actual displacement, which implies the possibility of the propagation delay of electromagnetic wave by the atmospheric condition.
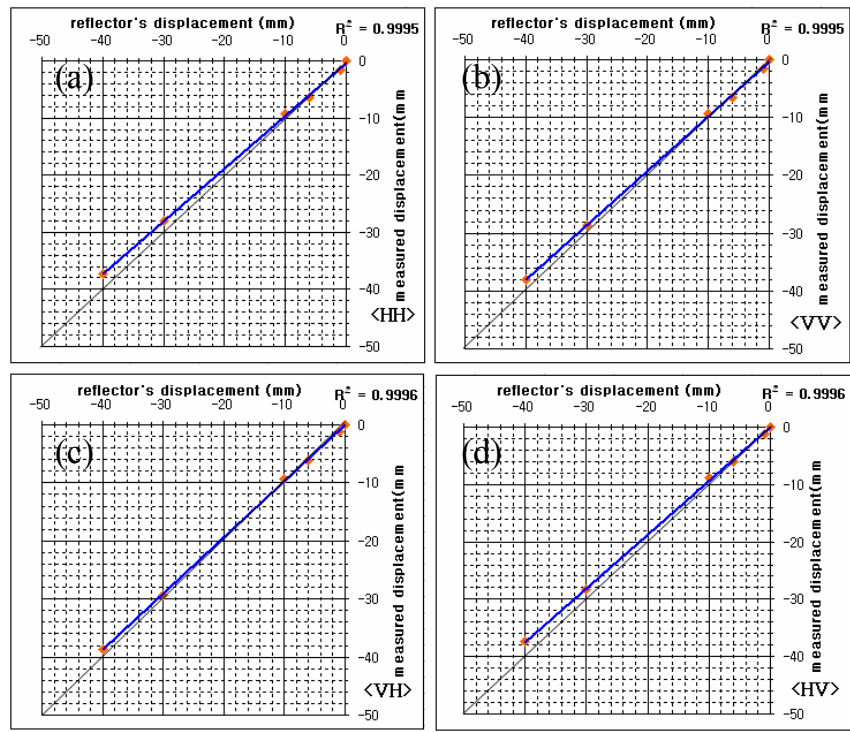

Fig. 4. Comparison of the GB-SAR measured and the actual displacement of a trihedral corner reflector. 


\section{ATMOSPHERIC CORRECTION}

Satellite and airborne SAR measurements can be strongly affected by atmospheric condition. Travel range of the GBSAR system is shorter than conventional SAR system, but we suspected the atmospheric condition is responsible for the displacement anomaly we have observed. Velocity of an electromagnetic wave depends on refractive index $n$ which is a spatiotemporal function of temperature, pressure and humidity [8]. Among them humidity has the most strong influence on the velocity [9].

Fig. 5 shows strong linear correlation between humidity record $(47 \sim 58 \%)$ and $\phi / R$ of several stationary targets used in this experiment, enabling the following linear regression meaningful:

$$
\phi / R=4 \pi(a h+b)
$$

where, $a$ and $b$ are the regression coefficients and $h$ is relative percentage humidity. Fig. 5(a) is the regression function using all-polarization data together. Total 96 phase measurements (4 stationary targets $\times 4$ polarizations $\times 6$ acquisitions). Fig. 5(b)-(d) are those using each polarization data separately. Using these atmospheric correction functions, we corrected the displacement measurement as shown in Fig. 6 that used all-polarization case and Fig. 7 that used function for each polarization. The regression parameters and rms errors after atmospheric corrections were summarized in Table II. The $\mathrm{R}^{2}$ values were very close to 1: from 0.9997 to 0.9999 and the rms errors reduced to below $1 \mathrm{~mm}$. However, there was little difference between the two regression methods, indicating that polarization dependence of phase delay is negligible.

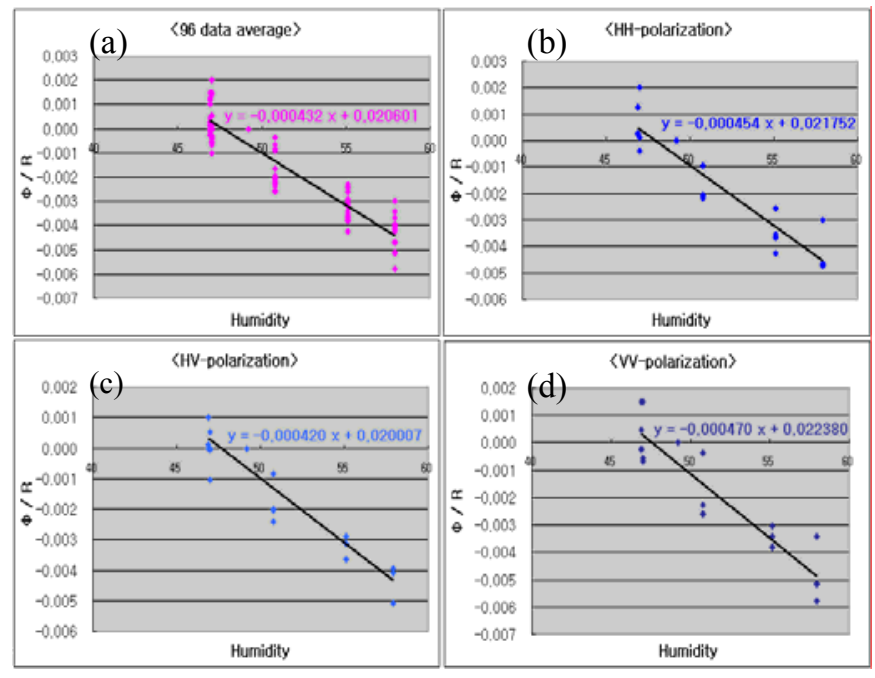

Fig. 5. Comparison of $\phi / R$ and humidity.
TABLE II. PARAMETERS OF THE ATMOSPHERIC CORRECTION FUNCTIONS $(47 \%<h<58 \%)$ AND RMS ERRORS

\begin{tabular}{|c|c|c|c|c|c|}
\hline & $\mathrm{a} \times 10^{5}$ & $\mathrm{~b} \times 10^{3}$ & \multicolumn{3}{|c|}{ RMS Error } \\
\hline Total & -3.44 & 1.64 & $\begin{array}{c}\text { Before } \\
\text { Correction }\end{array}$ & $\begin{array}{c}\text { Total } \\
\text { Correction }\end{array}$ & $\begin{array}{c}\text { Pol. } \\
\text { Correction }\end{array}$ \\
\hline HH & -3.61 & 1.73 & 1.560 & 0.188 & 0.219 \\
\hline VV & -3.74 & 1.78 & 1.124 & 0.482 & 0.618 \\
\hline VH & -3.13 & 1.50 & 0.764 & 0.918 & 0.783 \\
\hline HV & -3.34 & 1.59 & 1.446 & 0.488 & 0.471 \\
\hline
\end{tabular}
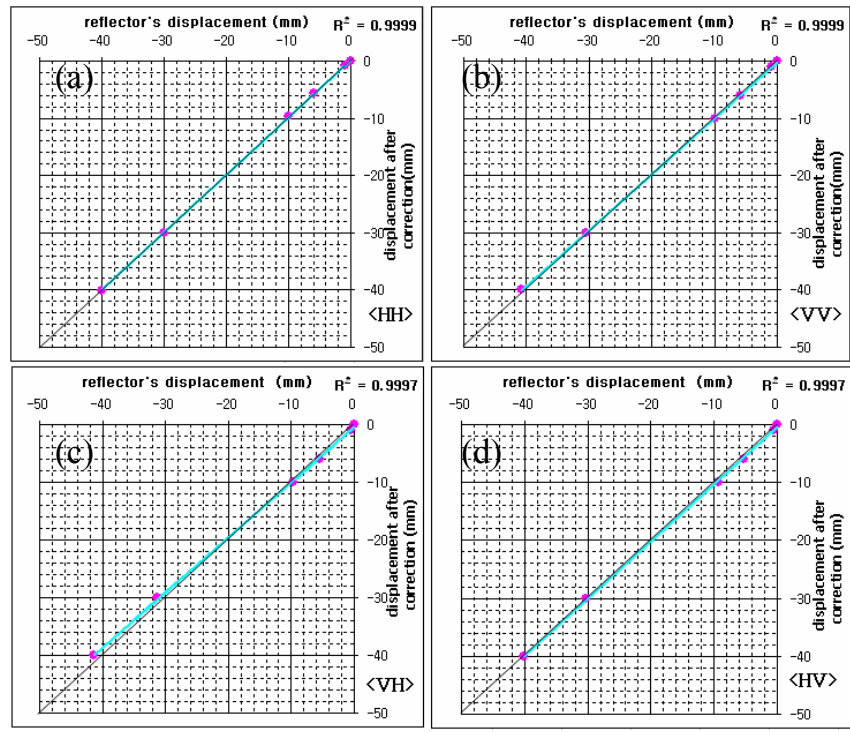

Fig 6. Comparison of displacements after atmospheric correction (using the regression of total data).

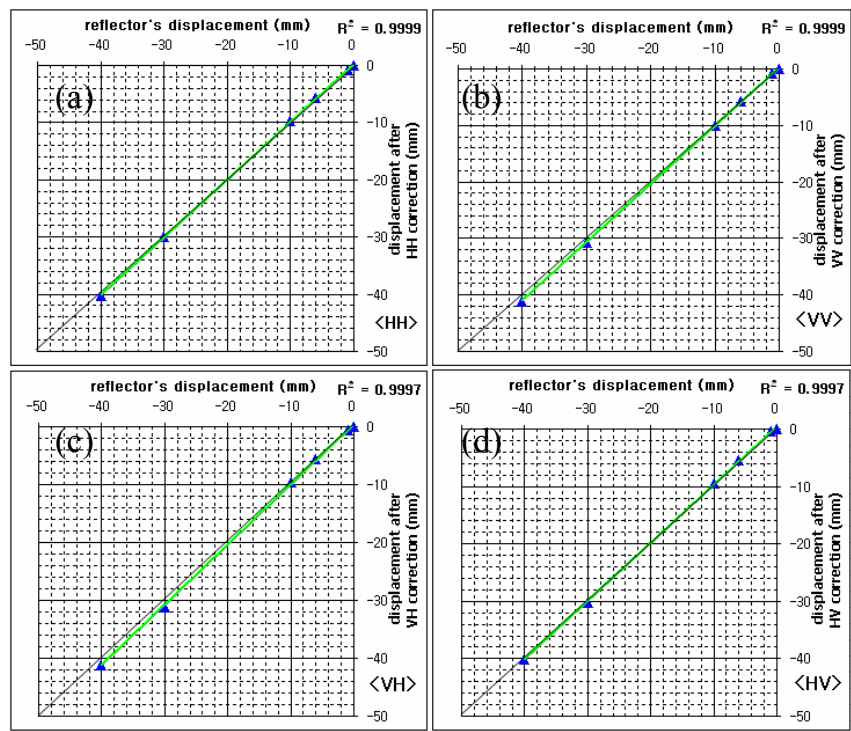

Fig 7. Comparison of displacements after atmospheric correction (using the regression of each polarization). 


\section{COMPARISON WITH X-BAND EXPERIMENT [8]}

Pipia et al., 2008 [8] performed a similar experiment and calculated an atmospheric correction algorithm by using $\mathrm{X}$ band $(9.65 \mathrm{GHz}) \mathrm{GB}-\mathrm{SAR}$ system in HH polarization. They obtained the following phase delay equation:

$$
\phi=-3.30 \times 10^{-3} R
$$

This was calculated by using regression of phase change of several permanent scatterers in different ranges. Temperature was $21^{\circ} \mathrm{C}$ and humidity was $44 \sim 59 \%$ during their experiment while no pressure information was given. For comparison we put the average humidity value of $52 \%$ to our equation (2) using the regression coefficients for $\mathrm{HH}$ polarization that resulted in

$$
\phi=-1.85 \times 10^{-3} R .
$$

We found that the coefficient is 1.79 times higher for the $\mathrm{X}$ band case than our C-band experiment. This can be explained by the following simple theory. The phase delay in a material with relative refractivity $n$ relative to vacuum can be expressed as:

$$
\phi=-\frac{4 \pi}{\lambda} R(1-n)
$$

It is known that $n$ is constant over wide range of spectrum of electromagnetic wave. Therefore, the ratio of coefficient $a$ is inversely proportional to wavelength. For the X-band and C-band, this ratio is 1.82 , which is similar to the observed ratio of 1.79. The slight mismatch might come from the model inaccuracy and unknown atmospheric condition, but it generally coincide with the above theory.

\section{CONCLUSION}

The measurement of displacement of a trihedral corner reflector at a range of $160 \mathrm{~m}$ by using GB-SAR showed high correlation of $R^{2}$ value from 0.9995 to 0.9996 , but also showed anomaly of up to $3 \mathrm{~mm}$ at $40 \mathrm{~mm}$ actual displacement. This anomaly was corrected by calculating atmospheric correction function of range and humidity, resulting in $R^{2}$ value of 0.9997 to 0.9999 for all polarization. Polarization dependence of atmospheric delay was detected but they are within error bound. These results showed that atmospheric correction is essential for the displacement measurement technique using SAR interferometry. Comparison of this C-band result with the $\mathrm{X}$-band one by [8] was in accordance with the wavelength dependency theory of phase delay. We concluded that atmospheric correction should be reinforced for spaceborne and airborne SAR interferometry.

\section{ACKNOWLEDGEMENT}

This research was supported by the Basic Research Project of the Korea Institute of Geoscience and Mineral Resources
(KIGAM): "The development of fusion techniques for precise subsurface imaging."

\section{REFERENCES}

[1] H. Lee, S. J. Cho, N. H. Sung and J. H. Kim, "Development of a GB-SAR(I): System configuration and interferometry." Korean Journal of Remote Sens., vol. 23, no. 4, pp. 237-245. Aug. 2007.

[2] H. Lee, S. J. Cho, N. H. Sung and J. H. Kim, "Development of a GB-SAR( II ): Focusing algorithm." Korean Journal of Remote Sens., vol. 23, no. 4, pp. 247-256. Aug. 2007.

[3] D. Leva, G. Nico, D. Tarchi, J. Fortuny-Guasch, and A. J. Sieber, "Temporal analysis of a landslide by means of a ground-based SAR interferometer." IEEE Trans. Geosci. Remote Sens., vol. 41, no. 4, pp. 745-757, Apr. 2003.

[4] D. Tarchi, H. Rudolf, G. Luzi, L. Chiarantini, P. Coppo, and A. J. Sieber, "SAR interferometry for structural changes detection: a demonstration test on a dam." International Geosci. Remote Sens. Symposium, vol. 3 no. 3, pp. 15221524, Jun. 1999.

[5] G. Luzi, M. Pieraccini, D. Mecatti, L. Noferini, G. Guidi, F. Moia, and C. Atzeni, "Ground-Based Radar Interferometry for Landslides Monitoring: Atmospheric and Instrumental Decorrelation Sources on Experimental Data." IEEE Trans. Geosci. Remote Sens., vol. 42, no. 11, pp. 2454-2466. Nov. 2004.

[6] M. Pieraccini, D. Tarchi, H. Rudolf, D. Leva, G. Luzi, and C. Atzeni, "Interferometric radar for remote monitoring of building deformations." Electronics Letters, vol. 36, no. 6, pp. 569-570. Mar. 2005.

[7] Z. S. Zhou, W. M. Boerner, and M. Sato, "Development of a ground-based polarimetric broadband SAR system for noninvasive ground-truth validation in vegetation monitoring." IEEE Trans. Geosci. Remote Sens., vol. 42, no.9, pp. 1803-1810, Sep. 2004.

[8] L. Pipia, F. Xavier, A. Albert, and L. M. Carlos, "Atmospheric Artifact Compensation in Ground-Based DInSAR Applications." IEEE Geosci. Remote Sens. Letters, vol. 5, no. 1, pp. 88-92. Jan. 2008.

[9] L. Noferini, M. Pieraccini, D. Mecatti, G. Luzi, C. Atzeni, A. Tamburini and M. Broccolato, "Permanent Scatterers Analysis for Atmospheric Correction In GroundBased SAR Interferometry.", IEEE Trans. Geosci. Remote Sens., vol. 43, no.7, pp. 1459-1471, Jul. 2005. 